\title{
Edward L. Davis, Society and the Supernatural in Song China
}

Honolulu, University of Hawai'i Press, 2001, XI+355 p. (bibliogr., annexes, glossaire, index)

\section{Vincent Goossaert}

\section{CpenEdition}

Journals

Édition électronique

URL : http://journals.openedition.org/assr/1626

DOI : 10.4000/assr.1626

ISSN : $1777-5825$

Éditeur

Éditions de l'EHESS

Édition imprimée

Date de publication : 1 avril 2002

Pagination : 87-151

ISBN : 2-222-96718-X

ISSN : 0335-5985

Référence électronique

Vincent Goossaert, "Edward L. Davis, Society and the Supernatural in Song China », Archives de sciences sociales des religions [En ligne], 118 | avril - juin 2002, document 118.14, mis en ligne le 14 novembre 2005, consulté le 21 septembre 2020. URL : http://journals.openedition.org/assr/1626 ; DOI : https:// doi.org/10.4000/assr.1626 
nautés institutionnalisées dans la période précédente (de 315 à environ 450).

Vincent Goossaert.

\subsection{4}

DAVIS (Edward L.).

Society and the Supernatural in Song China. Honolulu, University of Hawai'i Press, 2001, $\mathrm{XI}+355$ p. (bibliogr., annexes, glossaire, index).

La culture chinoise a toujours pratiqué sous diverses formes la possession, ce qui a conduit certains auteurs à parler du "substrat chamanique » de la religion chinoise. E.L.D. se propose de montrer à quel point la possession fut effectivement importante, mais réfute toute référence au chamanisme. Ce dont il parle n'est pas la transe contrôlée du chamane qui lui permet de voyager dans l'au-delà, mais la possession par une divinité du corps d'un individu, généralement un garçon ou un adolescent : tant qu'il est possédé, le médium n'a plus aucune volonté et n'est que le support de la divinité qui parle et agit par lui ; après le départ de la divinité, le médium n'a aucun souvenir de ce qui s'est passé.

La possession est par excellence la spécialité des médiums servant les cultes des villages, autour de divinités de la nature ou de profil démoniaque. Classiquement, ces médiums travaillent seuls. Or à l'époque des Song (960-1279), le monde des médiums entre en interaction avec la religion élitiste des prêtres taoïstes et bouddhistes pour donner naissance à un ensemble de rituels exorcistes. Dans ces rituels, un maître fait usage d'un ou plusieurs médiums, en provoquant leur possession par une divinité tutélaire propre au maître et qu'il guide dans le processus exorciste. La divinité tutélaire mène l'enquête et l'interrogatoire qui permet d'identifier l'esprit coupable de la souffrance du patient; parfois cet esprit est aussi forcé de posséder le médium pour être interrogé par le maître exorciste. C'est précisément les liturgies impliquant la possession contrôlée et le couple prêtre-médium que ce livre explore, en insistant sur leur contexte social. Le sujet n'avait jamais été traité sinon par de brèves allusions, et le présent livre occupe donc une place importante dans l'histoire du rituel et l'histoire sociale de la religion chinoise.

E.L.D. suggère à plusieurs reprises, et on ne peut que le suivre, que les traditions des médiums de village et les traditions élitistes des bouddhistes et des taoïstes ont toujours été en influence réciproque, et qu'on ne peut donc quasiment jamais trouver chacune d'elles à l'état pur. Ceci dit, il insiste très nettement sur la nouveauté de cette rencontre et de cette alliance entre prêtres et médiums à l'époque Song ; ce faisant, il semble insister sur leur différence et leur isolement aux périodes précédentes. L'image qu'il donne du clergé taoïste jusque sous les Song, une élite préservant un savoir ésotérique et cantonnée dans les institutions officielles, n'est pas tout à fait convaincante, du moins nécessiterait-elle une description plus complexe. Mais il remarque très justement que cette élite cléricale se définit notamment par une relation complexe avec la religion de village et ses médiums, à la fois hostile et cooptative. Le conflit apparaît plus facilement, mais en fin de compte, c'est sans doute la coopération qui constitue le phénomène le plus fondamental.

E.L.D. consacre une partie de son introduction à cette question de conflit et cooptation et, comme beaucoup d'auteurs publiant un premier livre, il se sent obligé d'essayer de détruire l'œuvre des grands anciens pour affirmer son apport - comme tous ces auteurs, il n'est guère convaincant dans cet exercice. Il propose en effet de définir deux approches du taoïsme, qu'il définit comme celle de Kristofer Schipper et de Michel Strickmann, le premier considérant le taoïsme comme l'émanation écrite de la religion populaire chinoise, et le second la définissant au contraire comme son ennemi irréductible. Il voit dans ces deux attitudes un excès dû à un usage excessif d'un type spécifique de source (Schipper et son terrain à Taïwan ; Strickmann et les textes révélés du IVe siècle). En réalité, ces querelles d'école n'existent pas (E.L.D. a appris auprès de Strickmann qui a appris auprès de Schipper) et tous les trois ont raison. La relation taoïsme - religion populaire a toujours été faite d'emprunts et de méfiance, mais, sur la longue durée, le rapprochement est de plus en plus fort. L'un des moments clés de ce rapprochement est précisément la mutation de la liturgie sous les Song qui intègre alors les divinités exorcistes.

Quoi qu'il en soit, E.L.D. est totalement convaincant quand il démontre que c'est bien sous les Song que se forment les rituels auxquels on assiste encore aujourd'hui dans les temples de village en Chine, et où les maîtres du taoïsme «vernaculaire » dirigent les médiums. Il rassemble au passage des matériaux montrant que les lignées (comme le Lüshan) de ce taoïsme vernaculaire connu par les travaux des anthropologues se forment aussi à ce moment. Plus généralement, son argument vient contribuer de manière très appréciable à un ensemble croissant mais encore limité de travaux qui mettent en évidence le passage pro- 
gressif, entre le $\mathrm{IX}^{\mathrm{e}}$ et le $\mathrm{XIII}^{\mathrm{e}}$ siècle, à l'état moderne de la religion chinoise. Il n'était pas dans le propos d' E.L.D. de donner un tableau complet de cette grande mutation historique, mais on peut rappeler que c'est aussi à cette période que se forment les communautés de culte territoriales, organisées en réseaux et en alliances, et dirigées par des notables laïques, que les monastères perdent progressivement leur statut de centre de la religion locale pour se concentrer sur leur fonction de formation des religieux et que la majorité du clergé devient les employés des temples dirigés par les laïcs. Ces communautés laïques de temples prennent le relais des anciennes paroisses de l'Eglise du Maître céleste. Les hiérarchies d'initiation des laïcs à des grades religieux disparaissent pour laisser place à des pratiques spirituelles diffusées librement, sans cérémonies d'initiation. Et différents groupes laïques se passent même de clergé, en communiquant directement avec les divinités par l'écriture inspirée, ou par le sacerdoce universel pratiqué par différents courants bouddhiques « sectaires ».

On voit donc à quel point cette mutation religieuse remet en question le rôle du clergé taoïste et bouddhique. Celui-ci ne perd pas vraiment de son prestige ou de ses attributions, mais se voit plus dépendant des communautés laïques. Ces communautés emploient d'ailleurs concurremment divers spécialistes, et les prêtres taoïstes et bouddhistes se trouvent en compétition avec un nouveau type de praticien, dont ils adoptent finalement la liturgie. Les chapitres 2 et 3 sont en effet consacrés à l'apparition d'un nouveau personnage, le maître exorciste, fashi. Une lecture fine des nombreuses anecdotes contenues dans l'incomparable recueil de faits divers religieux du XIII ${ }^{\mathrm{e}}$ siècle, le Yijian $z h i$, permet à E.L.D. de dresser un portrait de ces fashi. Ils sont taoïstes, ou bouddhistes, n'ont pas été formés dans les monastères, se soucient peu des règles et des écritures saintes, mais se consacrent entièrement au culte d'une divinité tutélaire, généralement martiale, et pratiquent des exorcismes et guérisons spectaculaires. Ils recrutent des enfants médiums localement. En réalité, ces fashi couvrent toute une gamme dans la sophistication théorique et liturgique et dans le style de vie, allant du médium au prêtre; chacun d'entre eux jouit du même statut social que sa clientèle propre et les clients des fashi vont des villageois aux élites urbaines. Fashi est d'ailleurs autant un rôle qu'une classe d'individu, car de nombreux prêtres taoïstes ou bouddhistes font les rituels des fashi (et deviennent donc provisoirement fashi) quand les laïcs le leur demandent. L'intégration des pratiques des fashi au sein du clergé taoïste traditionnel a été opérée essentiellement par l'institution des maîtres célestes et, en contrepartie, cette fusion a permis aux maîtres célestes d'asseoir leur domination sur le clergé taoïste (ce fait historique fondamental est évoqué par E.L.D. mais mériterait une étude à part entière). Plus encore, la liturgie exorciste (et son panthéon de divinités martiales) est intégrée au sein de la liturgie taoïste et bouddhiste traditionnelle ; E.L.D. le montre à la fin de son ouvrage au sujet de la liturgie pour les morts.

En bon savant américain, E.L.D. est soucieux de mener son récit dans le détail, mais aussi d'élaborer des théories. Le lieu où la passion théorique, en particulier politique, de E.L.D. se déploie complètement est la conclusion, qui s'éloigne des exorcismes de l'époque Song pour parler de la société civile en Chine contemporaine. On en retiendra que le rôle de la religion dans une « société civile » chinoise a été ignoré, ce qui est vrai, du fait de l'ignorance en matière de religion des historiens de la Chine moderne et contemporaine, mais là n'est pas le sujet du présent livre. E.L.D. a une plume alerte, et il le sait. Son style est très enlevé, parfois un peu précieux, mais très efficace pour rendre à une anecdote vieille de huit siècles un sens très immédiat.

Tout au long de son ouvrage, il lance des piques tout à fait explicites à ses collègues ; toutes ne sont pas convaincantes, mais le présent recenseur ne peut que l'approuver quand il dénonce l'obsession de l'historiographie de la Chine, en particulier de la période Song, pour le néo-confucianisme. De manière générale, il propose d'oublier la division de la religion chinoise en trois institutions (confucianisme, bouddhisme, taoïsme) pour adopter plutôt un modèle hiérarchique suivant les classes sociales. En haut de ce modèle se trouvent les élites : lettrés de carrière, prêtres taoïstes, moines bouddhistes des grands monastères, servant une clientèle aisée dans les grandes villes, dans un style de cour, dans un rapport au sacré tournant autour de l'éthique. En bas se trouvent les communautés de village, avec leurs médiums, leurs dieux farouches et leur rapport martial au sacré. $\mathrm{Au}$ milieu se trouvent divers acteurs qui font le lien entre les deux; réseaux de cultes locaux, lignages etc..., qui inventent aussi leurs propres liturgies, dont celle des fashi. C'est précisément ce moyen terme qu'il a cherché à évaluer, dans son rôle de médiation et de négociation culturelle.

Vincent Goossaert. 